\title{
La Empresa Agrícola
}

\author{
Por el Dr. LUIS GAZZOLO *
}

En estos momentos en los que en nuestro Perú se ha delineado una política de Reforma Agraria conviene que meditemos acerca del concepto de Empresa Agrícola. Existe en la actualidad la tendencia de considerar al Derecho Agrario o Rural, como el "Derecho de la Empresa Agrícola". Ante todo trataremos de precisar la noción de Empresa, para lo cual debemos confesar que es realmente difícil traducir en términos jurídicos la idea económica de dicha institución.

Los tratadistas consideran empresario a quien ejercita profesionalmente una actividad económica organizada para los fines de la producción o del cambio de bienes o servicios. Es obvio que dentro de este concepto queda enclavada la figura del empresario comercial; pero nó la del empresario agricola cuya actividad se concreta a sólo determinada especie de producción; de manera que si el mismo agricultor transforma o enajena sus productos no por ello se convierte en industrial o comerciante. Dice Giacomo Acerbo; "El concepto de empresa tiene doble significado: instrumental (organización del trabajo y de otros medios productivos) y Funcional o sea la actvidud profesional del empresario propiamente dicho" (1).

De manera pues, que del concepto general de Empresa esbozado por los tratadistas, es necesario delinear las diferencias esenciales con la. Eirrpresa Agrícola. Desde el punto de vista material se reconoce particularmente la naturaleza de la actividad agricola, pues cuando se habla de enipresario agrícola hay que pensar en una actividad dirigida al cultivo del campo, a la silvicultura, a la crianza de ganado y a las actividades conexas, es decir a las actividades que producen bienes agrícolas, cuya existencia está condicionada no sólo por el trabajo del hombre, sino también por las energías del mundo natural orgánico. Widar Cesarini Sforza, sostiene al respecto: "No se puede predeterminar el contenido de la actividad del industrial y del comerciante, que corresponde al órea entera del

* Catedrálico Principal de Derecho Rural en la Universidad Mayor de San Marcos. Antiguo Catedrático de las Facultades de Derecho y Ciencias Económicas de la Universidad Cátólica.

(1) Economia y Política Agraria.- Pág. 54- Edizione dell 'Tteneo. - Roma - 1960 
trabajo humano aplicado a transformar materias primas en medios o instrumentos para la satisfacción de las diferentes necesidades de la viáa. En cambio si se puede pre-establecer el contenido de la actividad del agri. cultor cuyas finaijadades se perpetían en el tiempo sin modificaciones sustanciales, y que, por consiguiente la diferencia de les industriaies a come:ciales, es actividad de carácter esencialmente conservador" (2).

Quiere decir pues, que al lado de la empresa comercial o industrial, tenemos la empresa agraria, eje de enorme valor en el movimiento rural moderno. Bruno Rossi para señalar el concepto fundamental de Empresa Agrciria, parte de la noción de Hacienda y sostiene: Que la hacienda agrícola está consiliuida for bienes, que no podrían entre ellos organizarse $Y$ conseguir su fin productivo, sin la obra de algunas personas físicas. No basta pues un complejo de bienes para que el fundo sea cultivacio, sino que son necesarios factores personales que pongan en movimiento a los bienes haciendales y los encaminen a la consecución de las finalidades deseadas. Entonces como sostiene Rossi: "La combinación de estos factores personales con los elementos patrimoniales de la Hacienda, da lugar a la Empresa". (3).

Hay sin embargo algunas otras notas saltantes que diferencian a la Empresa Agrícola de la Comercial, así por ejemplo estas últimaz tienen persoriería jurídica $y$ se inscriben en el Registro de Sociedades o Empresais, mientras que el emprescrio agrícola no está sujeto por ley a inscribirse en ditho Registro, a no ser que la empresa agricola hubiese tomado la vestimenta de una sociedad anónima, en cuyo caso por practicar actos de ccmercio escapa de los linderos de la empresa agrícola y se convierte en esencia en una empresa netamente comercial.

Debemos tener en cuenta que el agricultor, como sostiene Bassane. ili, "no es un intermediario en el cambio de bienes, sino el productor quv pone en circulación el bien nuevo dado por la tierra"; tiene pues, una de las extremidades de aquella larga cadena a través de la cual los bienes circulan de quienes los producen a quienes los consumen, constituyendo uno de los eslabones de dicha cadena el acto de enajenación del agii $Y$ en realidad la actividad negocial (que así la llamaremos porque no creemos que el acto que realiza es comercial) del agricultor se desenvuelve preferentemente en el sentido de la enajenación.

Normalmente adquiere en el mercado los bienes auxiliares, pero sólo en parte, porque el fundo mismo produce mucho de ellos (abonos, paja, heno, etc.). Es verdad que el progreso de la técnica ha introducido el empleo de nuevos procedimientos para la valorización del suelo y para el incremento de la producción, afines pero no idénticos a los del comercio y de la industria. Hoy el agricultor tiene necesidad de medios químicos y

\footnotetext{
(2) Sui caratteri differencicli dell impresa Agrícola.- En Revista de Diritio Agrario..Marzo 1947.- Pág. 31.- Roma.

(3) Diritto Agrario. - 1960.- Firenze.
} 
mezánicos, de productos de industrias especializadas y de otras empresas agricclas; ol recurrir pues, a los actos de aaquisición se ha converticio tam. bié.i en una necesidad para el empresario agrícola. Pero por un complejo de motivos, no acude al mercado libre sino que sigue caminos o vías preestablecidas: los implementos, aperos, máquinas, fertilizantes, abonos, insecticidas, etc. los procura al crédito o también al contado de las asociaciones o cooperativas agrícolas de las cuales forman parte.

Los actos de enajenación no entran ya más, en la masa de contratos de venta con un público predelerminado por vínculos de clieritela cambiante, desccnocida y que se renueva de año en año, todo lo contrario se desarrolla mediante asociaciones voluntarias o a través de complejas operaciones con instituciones pre-establecidas como el Banco de Fomento Agropecuario y las diversas "Desmotadoras", las que no sólo tratan de comprar toda la producción algodonera de nuestros grandes $\mathrm{y}$ pequeños propietarios rurales, sino que habilitan al agricultor a fin de que haga frente a las diversas necesidades de la campaña agrícola. Al mercado libre, solo se dirige el empresario rural para establecer relaciones menos importantes por su frecuencia, volumen y naturaleza de aquello que verdaderamente constituye el núcleo central de la actividad del empresario industrial $y$ comercial.

No menos importante, para resaltar las diferencias entre las dos empresas que tratamos, es la regulación del recurso de crédito. Las rutas del crédito comercial se han cerrado prácticamente a la empresa Agraria. El período breve y propio de las operaciones comerciales, no se concilian con el largo ciclo de producción en la agricultura. Hay que tener en cuenta que el agricultor no puede procurarse fácilmente fiadores o garontes, porque no vive entre hombrez de negocios $\mathrm{y}$, de otro lado la dispersión territorial de los fundos aumenta la dificultad de relaciones personales entre el empresario y las Instituciones de Crédito. Estas causas pues, han inflúcio en la adopción de un sistema diverso, que tiene como base garantías casi exclusivamente reales. El crédito es proporcionado al agricuitor por insiliuciones que efectúan préstamos regulados por legislación especial sobre crédito agrario y garantizados par privilegios legales o convencionales sobre el fundo o heredad, ganado, cosecha e implementos agrícolas (4).

También hay que poner en relieve, la circunstancia que en las diversas formas de empresas asociativas típicas de la agricultura, a las cuales dan oxigen los contratos de aparcería, yanaconaje y colonato, tiene como principal disciplina las relaciones internas entre los coempresarios, do modo que la actividad negocial queda como marginal de la empresa. Verbigracia en las empresas aparceras o de yanaconaje, notamos que el "lucro" y las ventajas que los asociados se prometen, casi nunca se consigue a través de la actividad negocial con terceros, sino sólo por el liso $Y$

(4) El Decreto Ley 14509 del Banco de Fomento Agropacuario establece que los préstamos se harán a los pequeños, medianos $y$ grandes agricultores $Y$. a corto, mediano y lar. go plazo fluctuando su duración entre los dos años como mínimo y los 20 como plazo máximo. 
goce ejercido colectivamente sobre bienes entregados por el concedente o yanaconizarte. La empresa Agraria constituye pues, en el fondo, el ejercicio de una actividad económica productiva. Su esencia principal es forma de usus del fundo o heredad, mientras que la empresa comercial es siempre una actividad desorrollada por "negotiationes". Nuestro Códigc de Comercio, parece haber intuido esta idea al precisar en el Art 321 inciso $2^{\circ}$ que: "No se reputarán mercantiles:

2 -Las ventas que hicieran los propietarios, labradores y ganaderos de los frutos o productos de sus cosechas o ganados o de las especies en que se les pague las rentas".

Por todas las razones expuestas, se presenta al empresario agrícola aislado de las corrientes mercantiles, desarrollándose su actividad preferentemente en el campo técnico antes que comercial.

En conclusión por el funcionamiento de la empresa agraria, es menester considerar a los factores personales que dan movimiento a los bienes que constituyen la Hacienda, llevándolos a la consecusión de los fines deseados y los factores patrimoniales constituídos por el capital efectivo y por la hacienda propiamente dicha. (5) Igualmente es indispensable que la Empresa cultive el fundo con finalidad productiva. Al respecto debemos señjlar, que los modernos tratadistas sostienen que no puede constituir empresa agrícola una actividad dirigida por ejemplo, al cultivo de un jardín o de un parque, porque no se ha efectuado con fines productivos, sino para entretenimiento y goce del propietario o del pueblo o aldea en donde se halla dicho parque o jardín. (6)

En nuestro país, los códigos no tienen títulos o capítulos dedicados a la Empresa Agraria, como sucede en la legislación italiana o francesa. Las disposiciones que existen se refieren concreta y direciamente a las empresas ccmerciales y sólo hay referencias indirectas a ellas en diferentes leyes. Así la ley 8687 la toca tangencialmente al señalar la pequeña, mediana y propiedad Agropecuaria extensiva. Igualmente la novísima ley del Banco de Fomento Agropecuario del Perú (Ley 14509) establece que esta institución, para determinar el tipo de préstamo y el monto del mismo teridrá en cuenta su finalidad y la categoría e importancia del derecho con que el soilciante explote la tierra. Pero es particularmente el art. 40 de la ley en referencia la que señala que: "Los prestatarios podrán ser en térmiros generales: PEQUEÑOS; los que trabajan explotaciones agrícolas, pecuarias o forestales de tipo familiar. MEDIANOS: los que trabajan explo. taciones agrícolas, pecuarias o forestales posibles de ser administradas personalmente por el conductor $y$ operadas con el auxilio de mano de obra contratada; y GRANDES; los que trabajan explotaciones que requiereir la crganización de empresa para su operación y administración. Corresponde-

(5) Hay diferencia entre Fundo o Haredad Y Hacienda. El primero es elemento territorial, casco propiamente dicho: la Hacienda esta constituida por conjunto de bienes (inplementos aperos, máquinas etc.) que se necesitan para que la tierra produzca.

(6) Esta tenciencia la sostiere Orlando Cascio en su "Corso di Diritto Agrario" pág. 31.Palermo 1952. 
rá al Banco calificar a los prestatarios según la precedente clasificación. Semejante corriente encontramos en todos los proyectos de Iey ce Reiorma Agraria que hasta el momento estan en estudio en las Comisiones ciel Congreso.

En el Perú la empresa agraria que más fuerza económica ha tenido y tiene hasta estos momentos, es la que se configura en la Sociedad o Companía (Art. 124 del C. de Comercio) sea cual fuere la forma que adopten (Colectivas, Comanditarias o Anónimas): siendo evidente que lodas ellas al ccnstituirse de conformidad con el Código de Comercio, son consideradas esencialmente mercantiles $y$ sus actos no son agrarios sino simplomente de comercio.

Dentro de estos lineamientos debemos considerar a todas las compañías agrícolas y ganaderas, muchas de ellas con arquitectura de grandes explotaciones o Empresas, como: "Casa Grande", Negociación Talam. bo Ltda., Negociación Azucarera Laredo S. A., Agrícola Pucaió S. A., Cartavio, Paramonga, etc., consideradas como tales no sólo por la normalidad de sus cultivos, sino también por los modos o sistemas de trabajo. Estas grandes empresas y en especial las que se constituyen adoptando la forma de Sociedad Anónima, según la nueva corriente de Reforma Agraria están obligadas a convertri sus acciones al portador en nominativas. Este ha sido el criterio del art. 11 del Proyecto de Ley de Reforma Agraria de 1960 (7) y éste parece ser también el deseo de los autores del novísimo Froyecto de ley de tierras que entrará en discusión a nuestro Parlamento. El último de los proyectos determina una modificación de las grandes empresas al señalar que "los técnicos, empleados y obreros tengan una farticipación efectiva en las utilidades, en el capital $y$ en la dirección de la Empresa".

Tan importantes como las empresas que hemos mencionado, son nuestras cooperativas agrícolas, a través de las cuales los campesinos o braceros se asocian para adquirir en propiedad o tomar en arrendamiento un fundo o heredad para explotarlo directamente. Mediante las cooperativas agrarias de producción, el agricultor obtiene un mejor precio en sus productos, evitando la intervención del acaparador, quien es el que casi siempre impone los precios a su antojo. En suma las cooperativas dejan sentir su influencia, pues con ellas disminuyen las tierras ociosas, convirtiér:dose en verdaderas empresas de actividad agrícola.

Se da también el caso de que muchas veces la empresa colectiva, resuelve el problema de la organización del trabajo, tal por ejemplo en la aparcería que es el tipo más perfecto de participación del trabajo en la Em-

(7) Art. 11.- "Las sociedades por acciones que después de entrar en vigencia esta ley llegasen a ser propietarias o explotádoras de predios rurales, o a tener su dirección o control por cualquier título, y las que se constituyan para esos fines a partir de la presente ley, deberán emitir sus acciones a nombre de personas naturales".

"Las sociedades que antes de la vigencia de esta ley tuviesen la propiedad, explotación, dirección o control indicados, deberán convertir en nominativas sus acciones al portador..." 
presa agrícola, o en el yanaconaje o colonato por desgracia tan difundido en nuestro país.

No podemos dejar de mencionar como formas particulares, a las empresas que tenuemente se encarnan en una familia campesina y a las que se cristalizan en las Comunidades de Indígenas o "Reuniones de familias unidas por el vínculo de la sangre" (8). Estas últimas son instituciones, casi siempre con fines agrarios amparadas por el Estado, porque constituyen la supervivencia del colectivismo agrario de la etapa incaica.

Aun cuando muchas comunidades han demostrado su anhelo de superución, utilizando la mecanización y el crédito agrícola como: Muquiyauyo. Pucará, Matahuasi, Chinchero, Ampay, etc., muchas otras son organismos en transición que sólo practican la agricultura de subsistencia, estando ayunas de espíritu de empresa, imponiéndose por consiguiente la ne. cesidad de la integración de las poblaciones indígenas, para que puedan desarrollar con eficacia los fines que se propone la empresa agrícola. Quizás la excepción esté constituíáa por la Comunidad de Vicos, a pocos kilómetros de Huaraz. Nacida a la luz del convenio Perú-Cornell en 1951, la naciente comunidad adquirió un fundo, pagando con ayuda del Institulo de Fieforma Agraria un millón de soles al contado y el saldo de medio millón en tres cuotas. La meta es formar una cooperativa de producción y lo primero que se hizo fué abolir radicalmente el servicio gratuito del campesino, pero manteniéndose la unidad de las tierras comunales. Cada comunero recibió en propiedad su parcela; pero aceptó la obligcción de seguir trabajando tres días a la semana en los cultivos $y$ demás labores comunales. Los fondos son para la comunidad que inclusive da préstamos a los comuneros a fin de que éstos exploten sus parcelas. Vicos tiene fama de ser el mejor centro productor de papas de todo el departamento de Ancash. Para los vicosinos es motivo de particular orgullo el considerar el sistema comunal bien llevado como una meta y no como un método fracasado.

Una singular forma de pequeña empresa de cultivo o ganadera, se presenta de vez en cuando, en aquella que es ejercida por una familia. El proyecto de ley de Reforma Agraria de 1960 la incluye dentro del artículo 169, al precisar las características de la Unidad Familiar que son: fanilia;

a. - Ser conducida por un agricultor labrador y los miembros de su.

b.-Absorber toda la fuerza de trabajo de la familia;

c.- No requerir el empleo de mano de obra extraña, salvo en determinados períodos de la campaña agrícola $y$ en proporción que no exceda del $25 \%$ de la capacidad de trabajo de la familia.

ch.-En condiciones de eficiencia razonable en el uso de los recursos productivos, proporcionar al agricultor ingresos netos que le permitan al sostenimiento de su familia en condiciones adecuadas, cumplir con las obligaciones correspondientes a la compra de la propiedad, y acumular cierto margen de ahorro". Estas mismas características han sido reprodu-

(8) H. Castro Pozo.- Nuestra Comunidad Inäígena. Limo 1924. 
cidas por la ley de Bases y la ley No 14444 referente a la Beforma Agraria de la Convención. Igualmente la ley del Banco de Fomento Agropecuario, en el título correspondiente al "Crédito Argícola y la Tenencia de la Tierra", considiera a esta minúscula empresa en el art. 40 al mencionar entre los prestatarios a "los que trabajan explotaciones agrícolas, pecuarias o forestales de tipo familiar".

Otra forma difundida en nuestro medio, de empresa familiar es la que se da en el yanaconaje. En efecto la ley que regula a esta arcaica instiución (Ley 10885) dispone que las labores efectuadas en la parcela se hagan por el yanacona y sus familiares, siendo motivo suficiente de rescisión de conirato el hecho de que el yanacona "abone el trabajo del cam$\mathrm{po}^{\prime \prime}$; vale decir pues, que esia ley ha convertido al yanacona y su modesta familia en el eje de la pequeña empresa agraria familiar.

Hasia el momento hemos hecho mención de la Empresa Agraria ejercida por particulares, es decir por personas de derecho privado; pero no. debemos dejar de lado a las actividades económicas de algunos organismos o entes públicos, los cuales en cierta forma pueden también considerarse empresas. Claro que son raras las empresas agrarias de entes o personas de Derecho Público, porque la conducción directa crea una administración compleja y difícil en su control y por ende, trata de ser evitada por dichos organismos. Estas instituciones que según el art. 41 de nuestro C.C. son las Municipalidades, Universidades y Corporaciones públicas, prefieren el sistema de conducción mediante el arrendamiento y, en este caso, quien resulta empresario efectivo es el arrendatario. De manera pues, que la empresa agrícola estatal resulia un organismo excepcional. Sin embargo este tipo de empresa surge, cuando es el medio previsto para la consecución del fin para el cual fue creada la Corporación. A este género pertenecer entre otros:

a.-Las Unidades técnicas de Colonización (Decreto Supremo del 5 de abiil de 1951), creadas con el propósito de estimular al profesional peruano para que pueda adquirir en propiedad lotes de terrenos de montaña, facilitóndoles de esta manera el desenvolvimiento de sus actividades en el campo de la producción agrícola, ganadera y forestal.

b.--La empresa Agrícola ejercida por el Centro de Colonización Oficial de Tingo María (Ley 8687 del $1^{\circ}$ de Julio de 1938) que ha establecido una granja de colonización y experimentación, encargada de la enseñan$z a$ de los métodos de cultivo, explotación de bosques y sistemas de crianza do ganado, por medio de ingenieros agrónomos ambulantes.

c.-El Instituto Técnico Químico Industrial del Oriente, creado por ley 7643. Sus funciones son la investigación y el descubrimiento de los valores comerciales y científicos de los productos naturales de la selva, ade más este Instituto ha dado fuerza y ha sido el gestor de la creación de un Servicio forestal en el Perú.

ch.-El Servicio de Reforestación Nacional, establecido por Decreto Miristerial de 17 de Abril de 1940, cuya finalidad es la formación de viveros en el Norte, Centro y Sur de la República y la distribución de las semiIlas forestales seleccionadas. 
d.-El Instituto de Reforma Agraria, organismo administrativo, que evidentemente está llevando a cabo la Empresa más grande a que pueda someterse el país: la Reforma Agraria. Este movimiento, que en nuestro modesto concepto, es una verdadera revolución sin sangre, ha comenzado en escala regional en el Cuzco, especialmetne en Lares, la Convención y se extenderá a todo el país, en cuanto se apruebe la ley de Reforma que con tarita ansiedad es esperada por los peruanos.

Terminaremos recordando que uno de los principios del Derecho Agrario es: la Protección a la Empresa Agrícola, entendiéndose que ésta debe ser brindada no sólo a la gran empresa, sino en forma especial a nuestro pequeño y mediano agricultor, a nuestro yanacona o aparcero que emplea el trabajo familiar en la tierra que cultiva. Claro que en nuestro caso, podríamos decir que esta pequeña empresa familiar se caracteriza por la atrofia de su actividad comercial y por su falta de preparación; pero ésto es precisamente lo que debemos subsanar, es necesario preparar a nuestros campesinos, educarlos e instruirlos en los métodos y sistemas modernos de técnica agraria y económica, tratando de una vez que comprenda que la tierra no debe ser considerada como una libreta de ahorros sins como empresa $Y$, cese de ser considerada pura renta fundiaria. Cuando ésto se logre quedará orientada la producción y la comercialización de los productos de nuestro suelo. 